\title{
Memória virtual Outubro teatral em linha
}

\section{Eunice Tudela de Azevedo}
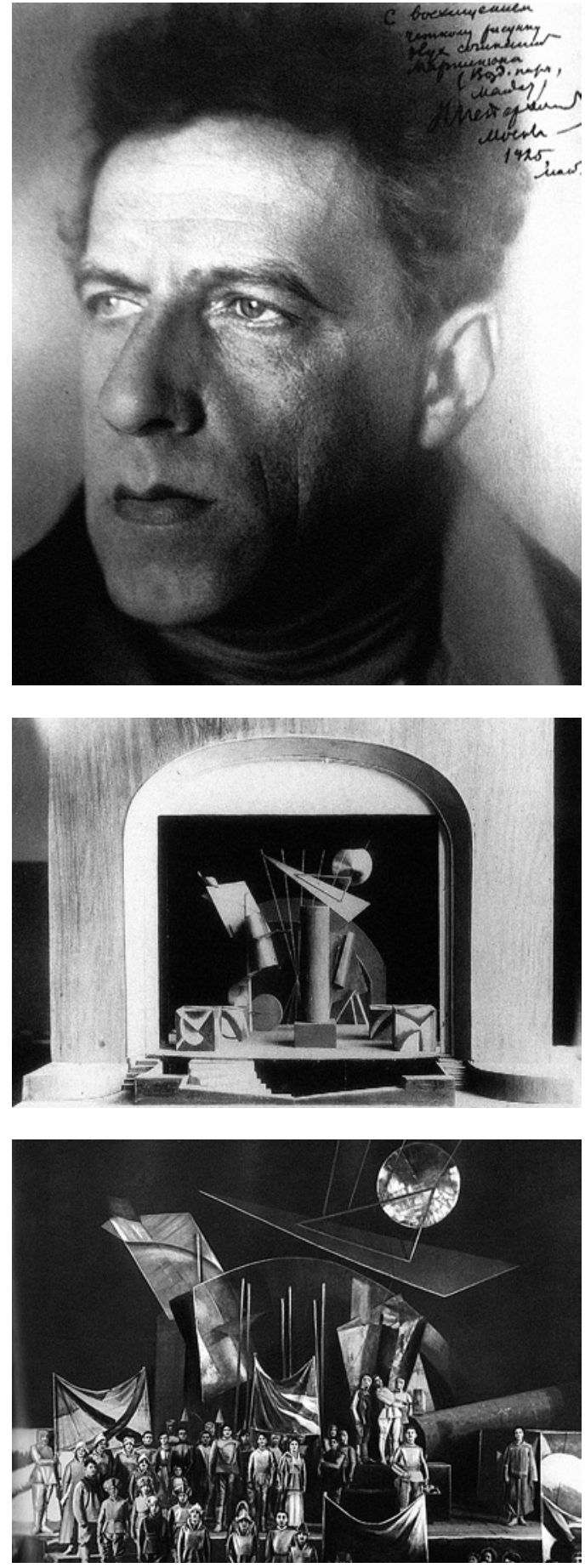

0 génio de Meyerhold

Dois sítios eletrónicos merecem destaque pelo importante e sugestivo material visual de teatro que disponibilizam: a agência de notícias russa RIA Novosti

[http://visualrian.ru/en] e a GloPAD - Global Performing Arts Database [http://www.glopad.org/].

Ambos oferecem, por exemplo, recursos indispensáveis para quem, por curiosidade ou necessidade, decide explorar o trabalho de Vsevolod Emilievich Meyerhold (1874-1940) e aprender como algumas das mais inovadoras manifestações teatrais da vanguarda russa se materializaram nas criações deste artista.

Ao longo de mais de três décadas, as suas encenações pautaram-se, principalmente, por um esforço constante de inovação, desconstruindo convenções, e mantendo um intenso diálogo com o seu tempo e com a realidade social e política que o envolvia. Nunca temeu a atualização dos clássicos, e sempre valorizou o espetáculo, a opsis, em detrimento da integridade do texto.

As mais significativas encenações de Meyerhold foram as que introduziram novidades, como a biomecânica ou o construtivismo cénico, dois dos grandes legados de Meyerhold, que marcaram presença em espetáculos com um tremendo impacto visual, como Le cocu magnifique (O magnífico cornudo) ou A morte de Tarelkin, ambos de 1922 e de autoria, respetivamente, de Fernand Crommelynck e .Alexander Sukhovo-Kobylin.

Dos seus espetáculos existem inúmeras descrições detalhadas, quer de contemporâneos seus - como o crítico Emmanuel Baskin ao recordar a apresentação da segunda versão de Mistério-bufo de Mayakovski, em 1921 (Rudnitsky 2000: 63) - quer de estudiosos da sua obra a partir de documentação iconográfica. Todavia, apesar da inegável utilidade destes testemunhos e descrições, é impossivel recusar a importância do confronto direto com os registos fotográficos das encenações de Meyerhold no que toca à compreensão do seu caráter inovador.

RIA Novosti (http://visualrian.ru/en)

Desde 1998, a RIA Novosti - a maior agência de notícias estatal da Federação Russa - renovada na sua forma e funcionamento, apresenta uma base de dados em rede com um acervo que continha inicialmente cerca de 250 mil documentos e com toda a informação disponibilizada em inglês. Desde então esse acervo cresceu

consideravelmente e apresenta-se espalhado por vários domínios, tão díspares como a arte e a cultura, a ciência e o desporto.
Vsevolod Meyerhold 1925

Maquete de cenário, por Dmitriev, para The Dawn, 1920

Fotografia de cena The Dawn, 1920

Eunice Tudela de Azevedo é Mestre em Estudos de Teatro pela Faculdade de Letras da Universidade de

Lisboa e participa com investigadora no projeto da CETbase do Centro de Estudos de Teatro da FLUL. 

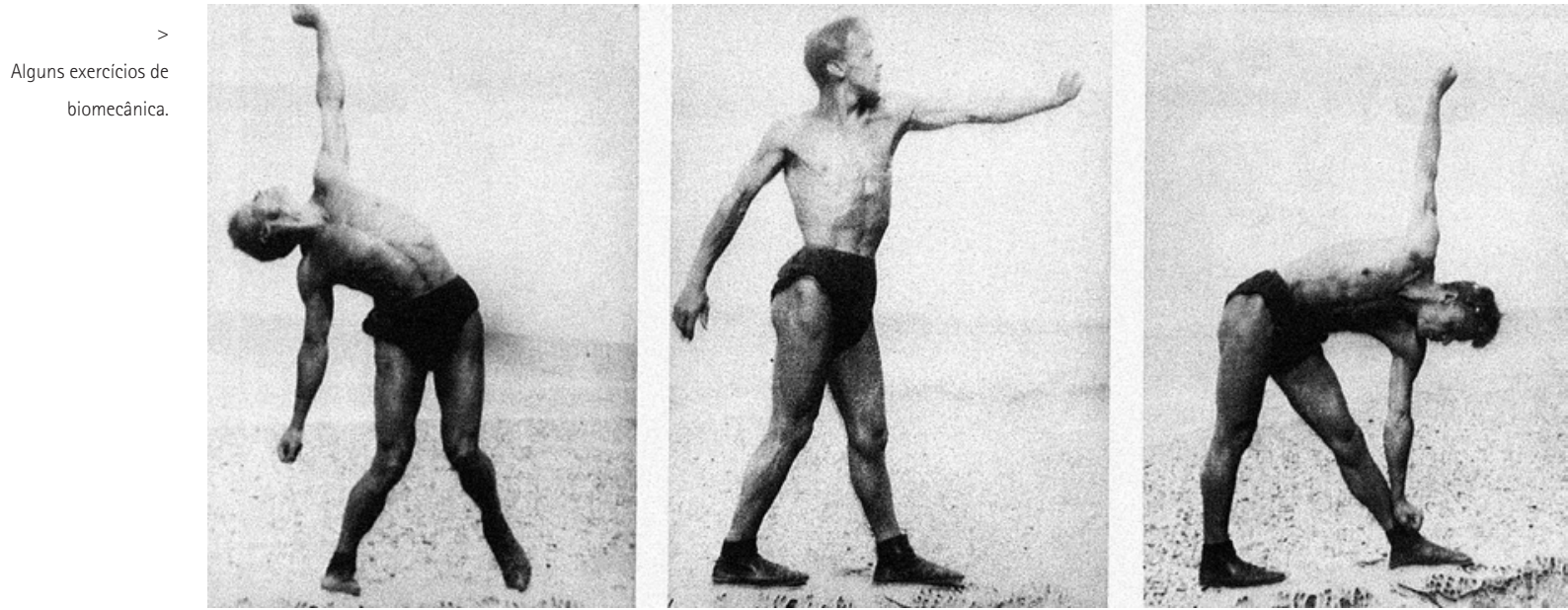

Fotografia de cena A morte de Tarelkin, 1922

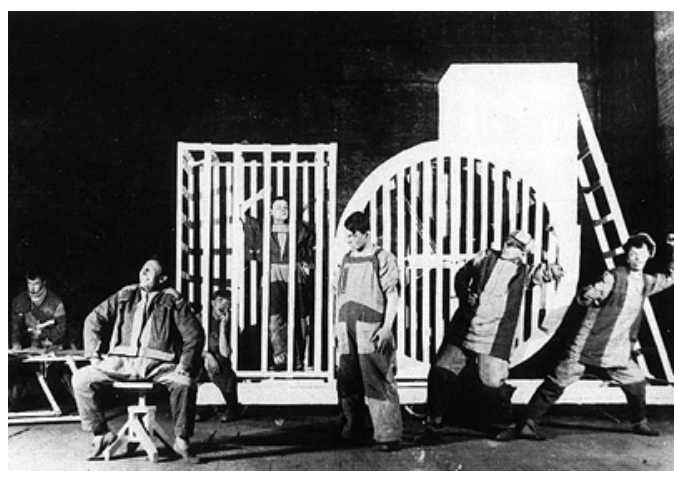

0 sítio eletrónico em questão contém a documentação visual da agência. Esta divide-se, quando se acede à página principal, em fotografia, vídeo, gráficos e cartoons. Ao selecionarmos o domínio da fotografia (photos), podemos constatar que este se divide em duas categorias - news e historical - o que possibilita ao utilizador compreender de imediato a natureza hibrida desta base de dados visual, uma vez que tanto podemos ter acesso às imagens da cobertura do evento mais atual da Rússia, como a imagens históricas, das quais as mais antigas remontam ao século XIX.

Ao efetuarmos a pesquisa sobre Meyerhold, rapidamente percebemos que obtemos documentação contemporânea - produto da cobertura de eventos que decorreram no Centro Meyerhold, em Moscovo -, mas também resultados diretamente relacionados com o encenador e com o seu trabalho, nomeadamente fotografias de cena, de ensaios e do próprio Meyerhold.

Apesar de permitir a visualização gratuita dos resultados de pesquisa, a RIA Novosti apenas permite baixar os documentos mediante pagamento - efetuado através de uma conta no site criada especificamente para o efeito - e que poderá variar consoante o objeto desejado e o fim ao qual se destina.

GloPAD (http://www.glopad.org/)

Encontra-se nesta base de dados uma grande quantidade de recursos em registos textuais, áudio, vídeo e fotográfico relacionados com artes performativas a nível mundial, bem como informações sobre artistas e produções. Produto de um contínuo processo de recolha e disponibilização de informação, este projeto norte-americano - que se encontra disponivel em seis línguas diferentes - teve

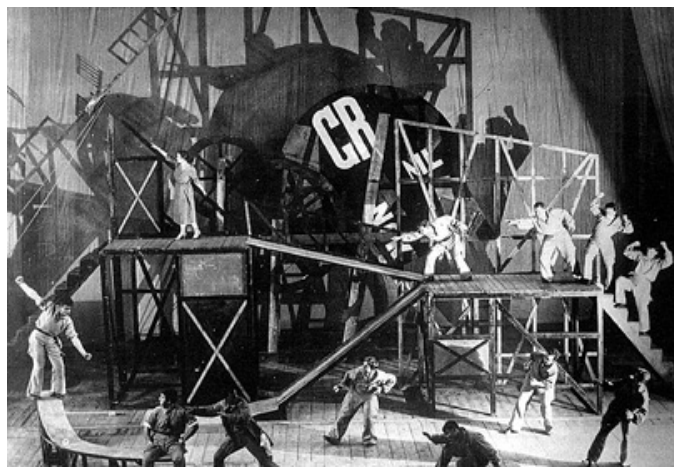

inicio, sob a tutela do Global Performing Arts Consortium (GloPAC), em 1998 e conta com o apoio da Cornell University e do Institute of Museum and Library Services. A consulta desta base de dados é bastante simples: basta ao utilizador introduzir, no campo único de pesquisa, a(s) palavra(s) do seu interesse, quer seja um ator, encenador ou figurinista, por exemplo, ou algum espetáculo ou texto em particular.

Ao efetuar a pesquisa relacionada com Meyerhold deparamos com uma documentação da mais variada natureza: maquetes de cenários, fotografias de cena, material promocional dos espetáculos, figurinos, etc. No entanto, é imperativo destacar a existência de documentação escrita e anotada pelo próprio Meyerhold bem como por atores que com ele trabalharam. Infelizmente, muitos destes documentos não são integralmente disponibilizados, tendo o utilizador apenas acesso à página de rosto. Todavia, cada objeto contém informação relativa aos respetivos direitos de autor e o utilizador tem sempre a possibilidade de contactar o centro de documentação para obter mais informação.

\section{Referências bibliográficas}

BRAUN, Edward (1998), Meyerhold on theatre, Londres, Methuen Drama. RUDNITSKY, Konstantin (2000), Russian and Soviet Theatre, Tradition and the Avant-Garde, Londres, Thames \&t Hudson. 